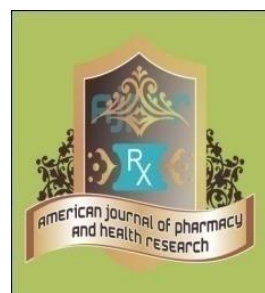

Review Article
AMERICAN JOURNAL OF PHARMACY AND HEALTH RESEARCH

www.ajphr.com

2020, Volume 8, Issue 7

ISSN: 2321-3647(online)

\title{
Comprehensive Review on Herbal Drug Interactions with Medicines used in Cardiovascular Disease Management
}

\author{
Sriram S ${ }^{1^{*}}$, Keziah Ann Babu ${ }^{1}$, Nanda kumar TR $^{2}$ \\ 1.College of Pharmacy, Sri Ramakrishna Institute of Paramedical Sciences, Coimbatore, \\ India \\ 2.Consultant Interventional Cardiologist, Department of Cardiology, Sri Ramakrishna \\ Hospital, Coimbatore, India
}

\begin{abstract}
The primary objective of this review is to address the issue of toxicity arising from herb-drug interactions (HDI) in patients taking complimentary systems of medicine and nutritional supplements along with prescribed medications in particular drugs for cardiovascular diseases. Patients tend to use herbal products with the belief that they are safe and harmless but this is not always true. A major population is known to have cardiovascular diseases for which they may be prescribed with multiple medications. Patients may develop undesired effects as result of concomitant use of prescription drugs with the so-called herbal products and may poorly respond to treatment. It is important to create patient understanding in the matter of HDI, so as to improve the clinical outcome. More attention to these interactions is also required on the part of healthcare professionals as well.
\end{abstract}

Keywords: Herb-Drug Interactions (HDI), Complementary medicine, alternative medicine, cardiovascular toxicity, Herbal remedies.

Please cite this article as: Sriram S et al., Comprehensive Review on Herbal Drug Interactions with Medicines used in Cardiovascular Disease Management. American Journal of Pharmacy \& Health Research 2020. 


\section{INTRODUCTION}

Cardiovascular diseases (CVDs) are disorders of the heart and blood vessels and they include: coronary heart disease; cerebrovascular disease; peripheral arterial disease; rheumatic heart disease; congenital heart disease; deep vein thrombosis and pulmonary embolism.

CVDs are a leading cause of death globally: more people die annually from CVDs than from most other causes. ${ }^{1}$ According to the National Health Interview Survey 2017, the prevalence of all types of cardiac diseases were $10.6 \%$; the corresponding prevalence of cardiac disease among whites, blacks, Hispanics, and Asians was 11.0\%, 9.7\%, 7.4\%, and 6.1\%, respectively. The prevalence of heart disease, coronary artery disease, hypertension, and stroke were higher in males $(11.8 \%$, $7.2 \%, 26.0 \%$, and $3.3 \%$, respectively) than in females $(9.5 \%, 4.2 \%, 23.1 \%$, and $2.5 \%$, respectively). ${ }^{2}$ Cardiovascular diseases (CVD) were estimated to occur in 422.7 million. ${ }^{3}$ Around 17.9 million people died from CVDs in 2016, representing $31 \%$ of all causes of death globally. Of these deaths, $85 \%{ }^{1}$ that is on an average 4 out of every 5 CVD deaths are primarily due to heart attacks and strokes, and of these deaths one third occur mostly in the elderly population. ${ }^{4}$ Of an average 58 million deaths globally in 2005, cardiovascular disease (CVD) accounted for 30\% among all the causes. ${ }^{5}$

Identifying those most susceptible to CVDs and ensuring appropriate management can help prevent deaths to a considerable extent. ${ }^{4}$ For secondary prevention of cardiovascular diseases in those with established disease, treatment with the following medications are necessary: aspirin, beta-blockers, angiotensin-converting enzyme inhibitors, statins etc. These agents are beneficial in preventing nearly $75 \%$ of recurrent cardiovascular events. ${ }^{1} \mathrm{CVD}$ already poses a significant economic burden on low- and middle-income countries. The facilities and resources available for their management in these regions are limited because of competing health priorities and health policies. Despite these issues, it is essential to find ways and means to manage CVDs at early stages else it will result in large and unavoidable complications of CVD maybe even death. ${ }^{5}$

\section{Plant products- myths and facts:}

Herbal remedies are considered to be green medicine. They are thought to be a more balanced and body-friendly approach being natural, safe, and alternative agents for a healthier lifestyle. This perception has led to the increased use of complementary medicines. ${ }^{6}$ Most people think these are harmless and are increasingly being used to cure ailments. This has led to the trend of selftreatment with herbal medicines available in the market. ${ }^{7}$ The general public believe that herbal medicines are safe because they are said to be of natural origin. This is just a misconception. ${ }^{8}$ Herbal or the so-called natural products are often adulterated with synthetic constituents. These 
herbal remedies are said to be devoid of side effects but the fact is that they cause undesirable effects such as nephrotoxicity, hepatotoxicity, cardiotoxicity, neurotoxicity and skin toxicities, when consumed in excess and also due to interaction with conventional drugs. ${ }^{3}$ These herbal products contain many natural derivatives with more than one active ingredient. This increases the likelihood of Herb-Drug Interactions (HDI). ${ }^{8}$ Plant products are safe, when used as per standard recommended, but the description "natural" doesn't always imply that it is safe. They are generally safe and non-toxic. ${ }^{9}$ The fact is that all medicines, both natural and synthetic, have side-effects if the dosage is not taken as prescribed. ${ }^{7}$ Few herbal preparations vary in potency, and many plant constituents are toxic in high doses, but when given in the right amount it can be effective for the treatment of certain conditions. ${ }^{9}$

\section{Herbs, cardiac drugs and their interactions:}

As the use of herbal products are on the rise and both the users and healthcare providers must be cautious of the major concerns associated with these products and the factors of safety and efficacy. All the natural molecules have one or more effect on the physiological system which increasing the probability of interaction. The effect of a conventional drug may be changed qualitatively or quantitatively by herbal constituents resulting in interaction between the two. Sometimes, if a moiety causes a permanent change in the body, interaction may occur due to that physiological change, even if the moiety is absent from the body. Some interactions are deliberated to achieve desired therapeutic effect while some others are unintended. These Herb-Drug Interactions may be attributable to drug and disease related factors such as age, gender, genotype, co-morbidities, dose, dosage form, route if administration, pharmacokinetics and pharmacodynamics etc.

Drug interactions have two basic underlying mechanisms; the pharmacokinetic and the pharmacodynamic interactions. Pharmacokinetic interactions result from alterations in absorption, distribution, metabolism, and excretion of drugs. Induction or inhibition of enzymes by herbal products, which in turn affects the metabolism of the co-administered drug resulting in toxicity, is a major cause for Herb-Drug Interaction. Pharmacodynamic interactions result when one drug changes the therapeutic or physiological effect of another. It could be addition, potentiation or antagonism of a drugs effect by another drug. ${ }^{3}$ The pharmacokinetics and pharmacodynamics of conventional drugs are well-studied, but this is not so with the herbal products. Studies on pharmacokinetics and pharmacodynamics of co-administered herbal products are underway due to their large variability and complexity of its components. ${ }^{10}$ 
Patients often do not mention to their physician or pharmacist, the nutritional and herbal supplements that they take concurrently with conventional medicines. This increases the chances of interactions between theses herbal products and the drugs.

Cardiotoxicity is a general term that refers to undesired changes in the structure and functioning of the heart, which can be detected by a variety of symptoms such as dry cough, inflammation of blood vessels, dysrhythmias, cardiomegaly, general weakness etc. ${ }^{3}$ Interactions between cardiac drugs and herbal products may either increase or decrease effects of the drug involved. It could lead to toxicity (say cardiotoxicity due to extensive pharmacological activity on the cardiovascular system) or subtherapeutic effects of the cardiac agent respectively.

Cardiovascular agents broadly fall under the following categories: antihypertensive agents, antianginals, cardiac glycosides, antihyperlipidemic agents, anticoagulants, antiplatelets, antiarrhythmic agents. These agents are associated with certain risks (side effects, narrow therapeutic index, drug interactions etc) and are to be prescribed and used after proper consideration of the therapeutic plan for each individual patient.

Here are a few commonly used herbal remedies that have been reported to cause interactions with drugs used for cardiovascular diseases. Glycyrrhiza glabra (liquorice) comprises of a glycoside known as glycyrrhizin or glycyrrhizic acid. It is used as flavouring agent, demusclent, expectorant and has anti-inflammatory. The constituent glycoside, is capable of enhancing sodium and fluid retention and promoting potassium depletion from the body. Therefore, it must be used with caution in patients with a history of either cardiovascular diseases. ${ }^{11}$ It is found to interact with antihypertensives, digoxin, loop and thiazide diuretics, atorvastatin, simvastatin, lovastatin. ${ }^{3}$

Ginkgo biloba consists of Ginkgolide- A, it is capable of inhibiting platelet-activating factor (PAF); decreases capillary fragility and blood loss from the capillary vessels. ${ }^{11} \mathrm{~W}$ arfarin, aspirin, cilostazol, thiazide diuretics, nicardipine, nifedipine, diltiazem, talinolol, propranolol have been seen to interact with its preparations. ${ }^{3},{ }^{12}$

Garlic (Allium sativum) is comprised of a thiosulphinate moiety called allicin. This is a $\mathrm{n}$ organosulphur phytochemical that is toxic to insects and the microorganisms. It protects against the Helicobacter pylori induced peptic ulcers, inhibits the proliferation of the cells present in the mammary glands, colon, and endometrium. It is found to reduce blood pressure in human beings and enhance induction of the nitric-oxide synthetase activity. Garlic distinctly causes the inhibition of the platelet aggregation by the arachidonic acid, epinephrine, and other platelet agonists and interacts with cilostazol, warfarin and atorvastatin. ${ }^{3,11}$ 
Aloe Vera consists of a large amount of water, amino acids, enzymes, lipids, sterols, and polysaccharides like pectin, hemicellulose, hydroxy anthraquinone derivatives namely Aloin A, Aloinoside A, Aloin B, Aloinoside B. It is widely used in nutraceuticals, topical preparations and cosmetics for its numerous protective properties. ${ }^{11}$. It is said to interact with antiplatelet agents. ${ }^{8}$

Soy based foods are processed or semi-processed products prepared from soya bean or Manchurian bean or Chinese pea. Soya bean is the seed of Glycine max and few other species. There have been studies showing that common use of the products may drastically reduce the risk of fracture in postmenopausal women by improving bone-mineral density. ${ }^{11}$ It interacts with anticoagulants. ${ }^{3}$ Senna has four principal constituents namely sennosides A, B, C and D, which are the dimeric glycosides with rhein and/or aloe-emodin moieties. Senna and its preparations, are widely used as purgative for constipation. ${ }^{11}$ Cassia senna interacts with cardiac glycosides. ${ }^{3}$

St.John's Wort, contains nine main groups of compounds namely, Phenylpropanes, Flavonol glycosides including hyperoside), Biflavones, Tannins and proanthocyanidins, Xanthones,Phloroglucinols (hyperforin), Essential oils, Amino acids, Naphthodianthrones (including hypericin) that contribute to its various properties. ${ }^{13}$ It is found to have interaction with many cardiovascular agents.

Digitalis is yet another essential herbal medicine used in congestive heart failure. It contains three important primary glycosides namely: Purpurea glycoside A, Purpurea glycoside B, and Purpurea glycoside $\mathrm{C}$, which when hydrolysed gives rise to digitoxin, digitoxin and digitalin respectively and on further hydrolysis digitoxigenin, gitoxigenin and gitaligenin or gitaloxigenin respectively. ${ }^{11}$ Digitalis preparations are found to interact with antiarrhythmic drugs. ${ }^{3}$

The ripe seeds of linseed contain cyanogenetic glycosides known as linamarin (or phaseolunatin).Its oil is used topically. Its constituents may interact with antiplatelets and anticoagulants. $^{3}$

Ginseng is widely used in traditional Chinese medicine. Its main constituents are Ginsenosides, Panaxosides and Chikusetsu Saponins. It is used as general tonic, stimulant, carminative and diuretic activities. ${ }^{11}$ They are seen to interact with narrow therapeutic index drugs like digoxin, warfarin. $^{3,12}$

Ginger a common component in Indian cuisine consists of Monocyclic Sesquiterpenoid, Zingiberene Ginger has Stomachic and Carminative properties. ${ }^{11}$ It interacts with anticoagulants and calcium channel blocker, nifedipine. ${ }^{3}$

Pepper contains Piperine. It is used as an insecticide. ${ }^{11}$ It is found to interact with verapamil, digoxin and propranolol. ${ }^{3}$ 
Curcumin, a phytochemical, is the major component of the spice 'turmeric'. It has (antiinflammatory and antioxidant properties. ${ }^{11}$ It is said to be a better anti-clotting agent in comparison to acety $1^{3}$

Salicylic acid i.e., aspirin) without gastric irritant side effects as aspirin. It may also be used in the prevention of the colon cancer. ${ }^{11}$ Losartan, rosuvastatin, warfarin, clopidogrel and talinolol are seen to interact with turmeric. ${ }^{3}$

Limonene is a chief constituent of grapefruit, orange and other citric fruits. ${ }^{11}$ Grapefruit contains organic compounds that are derivatives of furanocoumarin which may interfere with liver and intestinal enzymes and are believed to be primarily responsible for the most of its interactions with drugs. ${ }^{14}$ Grapefruit juice is commonly seen to interact with numerous drugs.

Menthone, a monocyclic terpene ketone. It is used widely as a flavouring agent and perfume.

Green tea consists of catechin (catechol) and caffeine as main constituents. It is used as an antidiarrheal agent.

Hesperidin, a flavanone glycoside is the most predominant flavonoid in lemons and sweet orange Citrus sinensis is used in along with ascorbic acid to reduce capillary fragility. It is indicated in the management of capillary fragility or permeability in hypertension and other cardiovascular diseases. ${ }^{11}$ Sweet orange interacts with aliskiren, a direct renin inhibitor.

Milk thistle contains Silybin. Silybin and its derivatives are widely used as liver protectants. ${ }^{11}$ It interacts with losartan. ${ }^{3}$

Chamomile is used as a herbal tea has terpenoids Bisabolol, which has anti-inflammatory and antispasmodic therapeutic properties. ${ }^{11}$ It interacts with warfarin. ${ }^{8}$

Phenolic acids, proanthocyanidins, resveratrol, and ellagic acid, arbutin are abundantly present in cranberry juice that prevent adherence of organisms to the cells lining the bladder, and the teeth, which ultimately lowers the incidence of urinary-tract infections (UTI) and the usual dental caries, reduce the oxidation of the LDL-cholesterol, minimize the formation of the specific cancerpromoting nitrosamines in diet. ${ }^{11}$ Cranberry juice is found to interact with warfarin. ${ }^{8}$ 
Table 1: Interactions of herbal plant products with drugs used for cardiovascular diseases(3)(6)(8)(12)(15)

\begin{tabular}{|c|c|c|}
\hline Herbal drug & Cardiac drugs & Interaction \\
\hline \multirow[t]{4}{*}{ Glycyrrhiza glabra (Liquorice) } & Antihypertensives & $\begin{array}{l}\text { Mineralocorticoid effects (sodium and water retention } \\
\text { and hypokalemia) of plant reduce the efficacy of the } \\
\text { drugs that use to lower blood pressure. }\end{array}$ \\
\hline & Digoxin (Cardiac glycoside) & $\begin{array}{l}\text { Increases pharmacodynamic effects of digoxin by } \\
\text { synergism. }\end{array}$ \\
\hline & Loop and thiazide diuretics & $\begin{array}{l}\text { Hypokalemic effect of the plant may increase the effect } \\
\text { of the loop and thiazide diuretics }\end{array}$ \\
\hline & $\begin{array}{l}\text { Atorvastatin, simvastatin, } \\
\text { (antihyperlipidemic agents) }\end{array}$ & $\begin{array}{l}\text { Enzyme inhibition (CYP2C9, CYP1A2, CYP2D6) and } \\
\text { induction (CYP3A4). }\end{array}$ \\
\hline \multirow[t]{5}{*}{ Ginkgo biloba (Maidenhair tree) } & Warfarin (Anticoagulant) & Increases anticoagulation and side effect of bleeding. \\
\hline & Aspirin, cilostazol (Antiplatelets) & additive inhibition on platelet aggregation \\
\hline & Thiazide diuretics & $\begin{array}{l}\text { Further increase in blood pressure } \\
\text { Decreasing the hypotensive activity of drugs }\end{array}$ \\
\hline & $\begin{array}{l}\text { Nicardipine, nifedipine, diltiazem } \\
\text { channel blockers) }\end{array}$ & $\begin{array}{l}\text { Possible increased antihypertensive activity resulting } \\
\text { from high bioavailability }\end{array}$ \\
\hline & Talinolol , Propranolol ( $\beta$-blockers) & $\begin{array}{l}\text { Possible increased antihypertensive activity resulting } \\
\text { from high bioavailability } \\
\text { Decreased the plasma concentrations of propranolol }\end{array}$ \\
\hline \multirow[t]{3}{*}{ Allium sativum (Garlic) } & Anticoagulant & $\begin{array}{l}\text { Increased anticoagulation effect of warfarin and may } \\
\text { increase the risk of bleeding }\end{array}$ \\
\hline & Atorvasatatin (antihyperlipidemic agent) & Enzyme inhibition (CYP2C9, CYP2D6, CYP3A4) \\
\hline & Cilostazol (Antiplatelet) & P-glycoprotein induction \\
\hline Aloe vera & Antiplatelets & Inhibits platelet aggregation \\
\hline Cardiac glycosides & Antiarrhythmic drugs & May enhance the hypokalemia-related arrhythmia \\
\hline $\begin{array}{lll}\text { Cassia } & \text { senna } & \text { (Alexandrian } \\
\text { senna) }\end{array}$ & Digitalis glycosides & $\begin{array}{l}\text { Risk of digitalis toxicity due to hypokalemic effect of } \\
\text { senna }\end{array}$ \\
\hline \multirow[t]{2}{*}{$\begin{array}{l}\text { Hypericum perforatum } \quad \text { (St. } \\
\text { John's Wort) }\end{array}$} & Warfarin and phenprocoumon (anticoagulant) & $\begin{array}{l}\text { May cause a moderate reduction in the anticoagulant } \\
\text { effects of the drug }\end{array}$ \\
\hline & $\begin{array}{l}\text { Simvastatin, rosuvastatin and atorvastatin } \\
\text { (antihyperlipidemic agent) }\end{array}$ & $\begin{array}{l}\text { May observe the increasing serum level of total } \\
\text { cholesterol due to decreased drug effects. }\end{array}$ \\
\hline
\end{tabular}




\begin{tabular}{|c|c|c|}
\hline & Nifedipine, verapamil (calcium channel blocker) & May decrease the bioavailability of drug \\
\hline & Ivabradine (Anti-anginal) & May decrease the bioavailability of drug \\
\hline & Talinolol (beta- blocker) & May decrease the bioavailability of drug \\
\hline & Digoxin (Cardiac glycoside) & Decreases levels of digoxin \\
\hline \multirow[t]{2}{*}{ Linum usitatissimum (Flax) } & Anticoagulants & $\begin{array}{l}\text { antiplatelet effects, should be concerned about the } \\
\text { possibility of prolonged bleeding }\end{array}$ \\
\hline & Antiplatelet drugs & $\begin{array}{l}\text { antiplatelet effects, should be concerned about the } \\
\text { possibility of prolonged bleeding }\end{array}$ \\
\hline \multirow[t]{2}{*}{ Panax ginseng (Asian ginseng) } & Warfarin (anticoagulant) & INR may decrease by concomitant usage. \\
\hline & Nifedipine (Calcium channel blocker) & Increase in blood levels. \\
\hline \multirow[t]{2}{*}{ Zingiber officinale (Ginger) } & Nifedipine (Calcium channel blocker) & May potentiate the antiplatelet effects. \\
\hline & Phenprocoumon (Anticoagulant) & Elevated INR , Enzyme inhibition \\
\hline \multirow[t]{3}{*}{ Piper longum (Long pepper) } & Verapamil (Calcium channel blocker) & Enzyme inhibition (CYP3A4. CYP2D6, CYP1A2) \\
\hline & Digoxin (Cardiac glycoside) & Enzyme inhibition (CYP3A4. CYP2D6, CYP1A2) \\
\hline & Propranolol (Beta blocker) & Enzyme inhibition (CYP3A4. CYP2D6, CYP1A2) \\
\hline \multirow[t]{5}{*}{ Curcuma longa (Turmeric) } & Losartan (Angiotensin receptor blocker) & $\begin{array}{l}\text { Enzyme inhibition (CYP3A4. CYP2B6, CYP1A2, } \\
\text { CYP2C19, CYP2C9) }\end{array}$ \\
\hline & Rosuvastatin (antihyperlipidemic agent) & $\begin{array}{l}\text { Enzyme inhibition (CYP3A4. CYP2B6, CYP1A2, } \\
\text { CYP2C19, CYP2C9) }\end{array}$ \\
\hline & Warfarin (Anticoagulant) & $\begin{array}{l}\text { Enzyme inhibition (CYP3A4. CYP2B6, CYP1A2, } \\
\text { CYP2C19, CYP2C9) }\end{array}$ \\
\hline & Clopidogrel (Antiplatelet) & $\begin{array}{l}\text { Enzyme inhibition (CYP3A4. CYP2B6, CYP1A2, } \\
\text { CYP2C19, CYP2C9) }\end{array}$ \\
\hline & Talinolol (Beta-blockers) & Decreases levels of talinolol \\
\hline \multirow[t]{2}{*}{$\begin{array}{lll}\text { Fucus } & \text { vesiculosus } & \text { (Bladder } \\
\text { wrack) } & & \end{array}$} & Amiodarone (Antiarrhythmic) & $\begin{array}{l}\text { Enzyme induction (CYP1A), Enzyme inhibition } \\
\text { (CYP2C9) }\end{array}$ \\
\hline & Valsartan (Angiotensin receptor blocker) & $\begin{array}{l}\text { Enzyme induction (CYP1A), Enzyme inhibition } \\
\text { (CYP2C9) }\end{array}$ \\
\hline Salvia miltiorrhiza (Red sage) & Warfarin (Anticoagulant) & $\begin{array}{l}\text { Increased anticoagulation, Inhibition of platelet } \\
\text { aggregation }\end{array}$ \\
\hline Pueraria montana (Kudzu) & Warfarin (Anticoagulant) & $\begin{array}{l}\text { Transport and enzyme inhibition (CYP2D6, CYP3A4), } \\
\text { enzyme induction(CYP1A2). }\end{array}$ \\
\hline
\end{tabular}




\begin{tabular}{|c|c|c|}
\hline \multirow[t]{5}{*}{ Citrus paradisi (Grapefruit) } & $\begin{array}{l}\text { Felodipine , nislodipine (Calcium channel } \\
\text { blockers) }\end{array}$ & $\begin{array}{l}\text { Increases effect of felodipine, increased bioavailability } \\
\text { of nislodipine. }\end{array}$ \\
\hline & Talinolol (Beta blocker) & Decreases blood levels. \\
\hline & Aliskiren (Direct Renin Inhibitor) & Decreased blood levels \\
\hline & $\begin{array}{l}\text { Atorvastatin, Lovastatin } \\
\text { Simvastatin (antihyperlipidemic agents) }\end{array}$ & Increase in bioavailability. \\
\hline & Warfarin (Anticoagulant) & Increases in effect of warfarin. \\
\hline $\begin{array}{l}\text { Mentha piperita } \\
\text { (Peppermint) }\end{array}$ & $\begin{array}{l}\text { Felodipine } \\
\text { (Calcium channel blocker) }\end{array}$ & $\begin{array}{l}\text { Enzyme inhibition (CYP3A4), P-glycoprotein } \\
\text { induction, Increases the levels of drugs metabolized. }\end{array}$ \\
\hline \multirow[t]{4}{*}{ Camellia sinensis (Green Tea) } & Digoxin (Cardiac glycoside) & P-glycoprotein induction, digoxin uptake inhibition \\
\hline & Nadolol (Beta blocker) & $\begin{array}{l}\text { Intestinal organic transport inhibition, decreased blood } \\
\text { levels. }\end{array}$ \\
\hline & Warfarin (Anticoagulant) & $\begin{array}{l}\text { Reduces the anticoagulant effect of warfarin, decreases } \\
\text { INR. }\end{array}$ \\
\hline & Rosuvastatin (antihyperlipidemic agent) & Intestinal organic transport inhibition \\
\hline \multirow[t]{2}{*}{ Malus pumila (Apple) } & Atenolol (Beta blocker) & Decreases systemic bioavailability. \\
\hline & Aliskiren (Direct renin inhibitor) & Decreased bioavailability. \\
\hline $\begin{array}{l}\text { Schisandra chinensis } \\
\text { flavour berry) }\end{array}$ & Talinolol (Beta blocker) & P-glycoprotein inhibition \\
\hline Citrus sinensis (Sweet orange) & Aliskiren (Direct renin inhibitor) & Transport inhibition, decreased blood levels. \\
\hline Silybum marianum (Milk thistle) & Losartan (Angiotensin receptor blocker) & \begin{tabular}{|l}
$\begin{array}{l}\text { Increased blood levels with increase } \\
\text { antihypertensive effects. }\end{array}$ \\
\end{tabular} \\
\hline $\begin{array}{l}\text { Matricaria } \\
\text { chamomilla(Chamomile) }\end{array}$ & Warfarin (Anticoagulant) & Over anticoagulation \\
\hline $\begin{array}{l}\text { Vaccinium macrocarpon } \\
\text { (Cranberry) }\end{array}$ & Warfarin (Anticoagulant) & Increases effects of warfarin. Enzyme inhibition. \\
\hline $\begin{array}{l}\text { Angelica } \\
\text { ginseng) }\end{array}$ sinensis $\quad$ (Female & Anticoagulants & May have anticoagulant actions \\
\hline $\begin{array}{ll}\text { Eleutherococcus } & \text { senticosus } \\
\text { (Siberian Ginseng) } & \end{array}$ & Digoxin (Cardiac glycoside) & $\begin{array}{l}\text { Increased levels of digoxin have been associated with } \\
\text { ingestion. }\end{array}$ \\
\hline Glycine max (Soy) & Warfarin (Anticoagulant) & $\begin{array}{l}\text { Decreased INR has been reported in a patient under } \\
\text { warfarin therapy }\end{array}$ \\
\hline
\end{tabular}




\section{CONCLUSION:}

In clinical practice, very few Herb-Drug Interactions are identified, as patient details on the use of complementary medicines are often neglected. This necessitates for the collection of subjective data on the use of alternative systems of medicine, OTC drugs and diet from patients prior to making a therapeutic plan especially for prevalent diseases like cardiovascular disorders. Clinical researcher must include studies on effect of drugs in presence of a variety of foods and plantproducts. HDI require to be studied at the molecular level although there maybe complex constituents involved. Adverse drug events arising due to HDI must be reported then and there so that signals can be generated and evidences gathered. Interactions of drugs with plant-based products require more vigilance.

\section{ACKNOWLEDGEMENT}

This review was supported by the College of Pharmacy, Sri Ramakrishna Institute of Paramedical Sciences, Coimbatore \& under the Tamilnadu Dr.MGR Medical University, Chennai.

\section{REFERENCES:}

1. https://www.who.int/en/news-room/fact-sheets/detail/cardiovascular-diseases-(cvds)

2. Virani SS, Alonso A, Benjamin EJ, Bittencourt MS, Callaway CW, Carson AP, et al. Heart disease and stroke statistics_-2020 update: A report from the American Heart Association. Circulation. 2020. 139-596 p.

3. Adiloğlu S, I, Yu C, Chen R, Li JJ, Li JJ, et al. The Clinical Importance of Herb-Drug Interactions and Toxicological Risks of Plants and Herbal Products We are IntechOpen , the world' $s$ leading publisher of Open Access books Built by scientists, for scientists TOP $1 \%$. Intech [Internet]. 2012;i(tourism):13. Available from: http://dx.doi.org/10.1039/C7RA00172J\%0Ahttps://www.intechopen.com/books/advance d-biometric-technologies/liveness-detection-inbiometrics\%0Ahttp://dx.doi.org/10.1016/j.colsurfa.2011.12.014

4. https://www.who.int/health-topics/cardiovascular-diseases/\#tab=tab_1

5. https://www.who.int/cardiovascular_diseases/guidelines/Full text.pdf

6. Costache II, Miron A, Hăncianu M, Aursulesei V, Costache AD, Aprotosoaie AC. Pharmacokinetic Interactions between Cardiovascular Medicines and Plant Products. Cardiovasc Ther. 2019;2019.

7. https://www.apollodiagnostics.in/general-health/ayurveda-myths-facts/

8. Izzo AA. Interactions between herbs and conventional drugs: Overview of the clinical data. Med Princ Pract. 2012;21(5):404-28. 
9. https://bloominstitute.ca/common-myths-about-herbal-medicine/

10. Zuo Z, Huang M, Kanfer I, Chow MSS, Cho WCS. Herb-drug interactions: Systematic review, mechanisms, and therapies. Evidence-based Complement Altern Med. 2015;2015:239150.

11. Ashutosh Kar. Pharmacognosy and phytobiotechnology. second edi. Available from: New Age International Publishers

12. Lim JW, Chee SX, Wong WJ, He QL, Lau TC. Traditional Chinese medicine: Herb-drug interactions with aspirin. Singapore Med J. 2018;59(5):230-9.

13. Henderson L, Yue QY, Bergquist C, Gerden B, Arlett P. St John's wort (Hypericum perforatum): Drug interactions and clinical outcomes. $\mathrm{Br} \mathrm{J}$ Clin Pharmacol. 2002;54(4):349-56.

14. https://en.wikipedia.org/wiki/Grapefruit-drug_interactions

15. https://reference.medscape.com/drug-interactionchecker.

AJPHR is

Peer-reviewed

monthly

Rapid publication

Submit your next manuscript at

editor@ajphr.com / editor.ajphr@gmail.com 